\title{
Salt-induced Formation of Uniform Fiber-like SBA-15 Mesoporous Silica Particles and Application to Toluene Adsorption
}

\author{
Shiori Kubo, Katsunori Kosuge \\ Research Institute for Environmental Management Technology, \\ National Institute of Advanced Industrial Science and Technology, 16-1 Onogawa, \\ Tsukuba, Ibaraki, Japan
}

Supporting Information

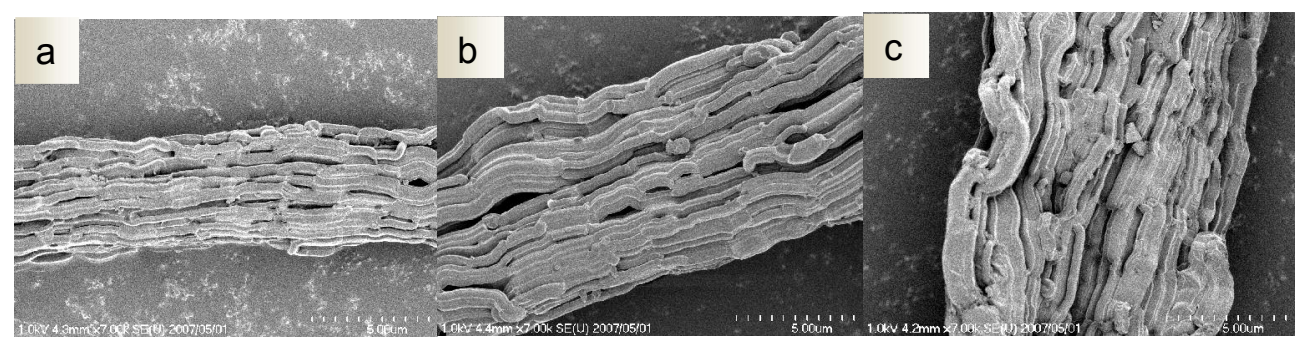

Figure S1. FE-SEM images of synthesized SBA-15 mesoporous silica (a) without addition of $\mathrm{NaCl}$, (b) with the addition of $\mathrm{NaCl}$ at a molar ratio to $\mathrm{Si}$ of 1.5 , and (c) with the addition of $\mathrm{NaCl}$ at a molar ratio to $\mathrm{Si}$ of 3.0, respectively. 


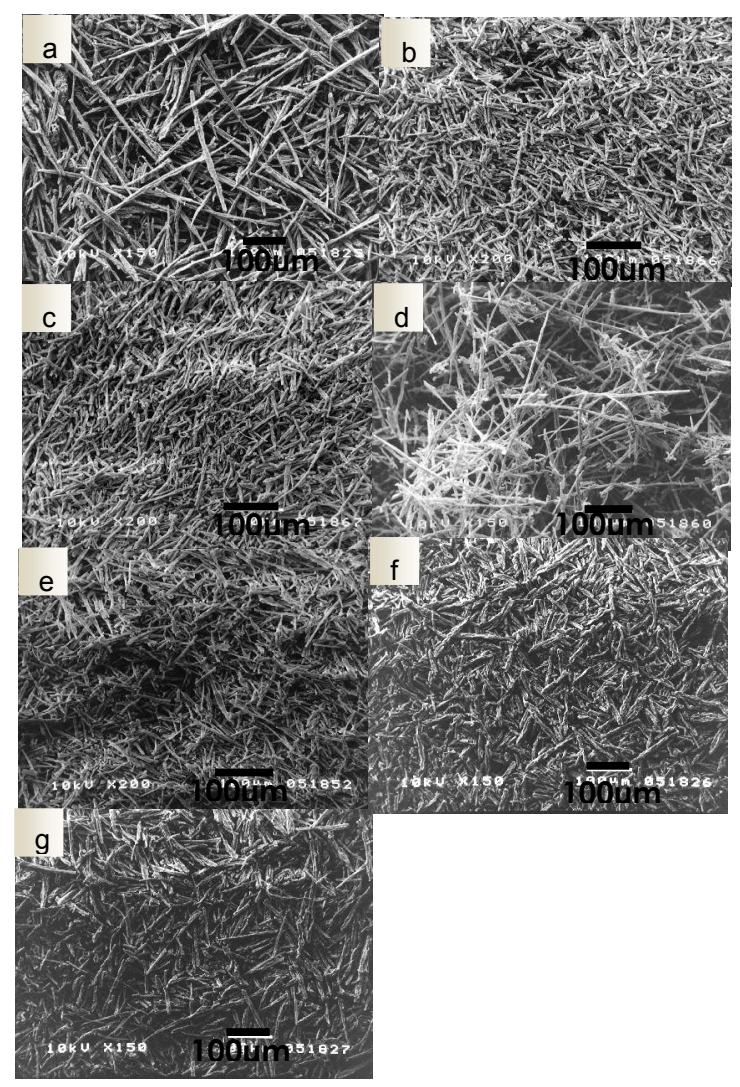

Figure S2. SEM images of synthesized SBA-15 mesoporous materials with different salt species; (a) $\mathrm{KCl}$ (b) $\mathrm{AlCl}_{3}$ (c) $\mathrm{CoCl}_{2}$ (d) $\mathrm{CaCl}_{2}$ (e) $\mathrm{NiCl}_{2}$ (f) $\mathrm{Na}_{2} \mathrm{SO}_{4}$ and (g) $\mathrm{NaNO}_{3}$.

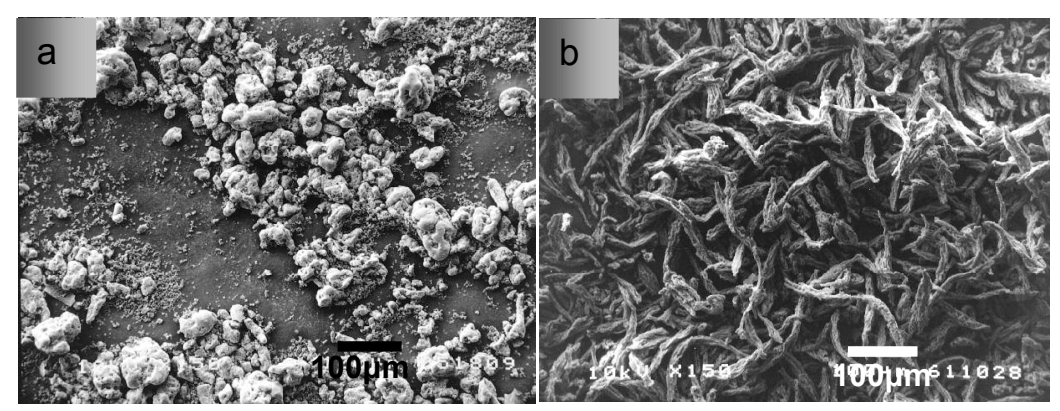

Figure S3. SEM images of mesoporous silica particles synthesized with a stirring time of (a) 30 min and (b) 40 min. 


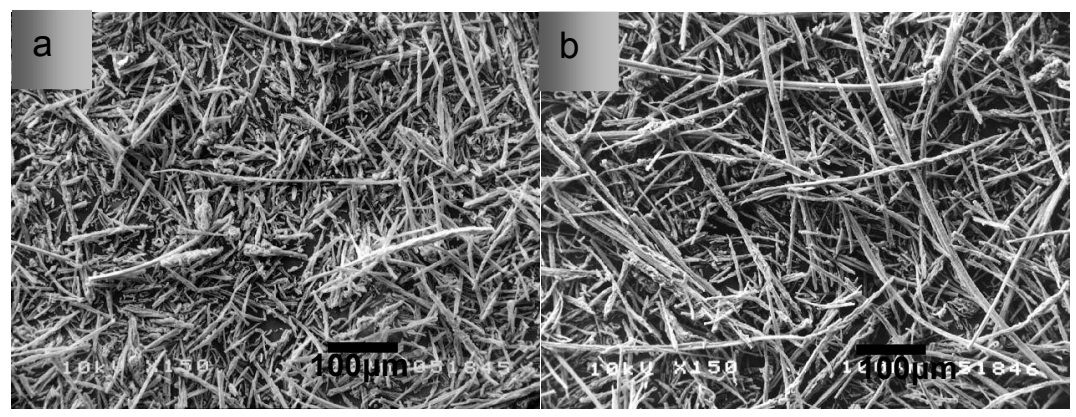

Figure S4. SEM images of mesoporous silica particles synthesized with the addition of $\mathrm{NaCl}$ at molar ratios to $\mathrm{Si}$ of 0.56 (a) and 1.0 (b).

Table S1. Pore properties of synthesized SBA-15 mesoporous silica using a variety of inorganic salt species

\begin{tabular}{|c|c|c|c|c|}
\hline $\begin{array}{c}\text { salt } \\
\text { species }\end{array}$ & $\begin{array}{l}V_{\text {micro }} \\
(\mathrm{ml} / \mathrm{g})\end{array}$ & $\begin{array}{c}V_{\text {meso }} \\
(\mathrm{ml} / \mathrm{g})\end{array}$ & $d(n m)$ & $\begin{array}{c}S_{B E T} \\
\left(m^{2} / g\right)\end{array}$ \\
\hline $\mathrm{KCl}$ & 0.13 & 0.67 & 6.82 & 804 \\
\hline $\mathrm{AlCl}_{3}$ & 0.15 & 0.72 & 7.06 & 887 \\
\hline $\mathrm{NiCl}_{2}$ & 0.14 & 0.69 & 6.82 & 859 \\
\hline $\mathrm{CaCl}_{2}$ & 0.14 & 0.71 & 7.06 & 869 \\
\hline $\mathrm{CoCl}_{2}$ & 0.16 & 0.74 & 7.06 & 928 \\
\hline $\mathrm{Na}_{2} \mathrm{SO}_{4}$ & 0.17 & 0.60 & 7.06 & 838 \\
\hline $\mathrm{NaNO}_{3}$ & 0.13 & 0.75 & 7.06 & 878 \\
\hline
\end{tabular}

